\title{
The Bacteriostatic Action of Phenol, Benzoic Acid and Related Compounds on Bacterium aerogenes
}

\author{
By R. G. H. BARBOUR AND J. M. VINCENT \\ School of Agriculture, University of Sydney, New South Wales, Australia
}

SUMMARY : A method was developed that permitted the immediate and relatively uncomplicated study of the inhibition of Bacterium aerogenes during the logarithmic growth phase. With the ten aromatic compounds tested the linear growth rate was immediately established in the presence, as well as in the absence, of inhibitor.

The results with Bact. aerogenes, as well as some similar determinations with Aspergillus niger, using $\mathbf{5 0} \%$ inhibition as criterion, suggest that in the phenols and in the acids, considered separately, there is a reasonably inverse relationship between inhibiting potency and water solubility. Substitutions that lead to an ortho-relationship between hydroxyl and carboxyl groups do not lessen but rather increase potency; meta- and para-substitutions of these groups lessen potency.

On the hypothesis that inhibition is proportional to the number of inhibitor molecules adsorbed at the surface of a susceptible metabolic system, potency can be analysed in terms of two factors: $(a)$ the ability to adsorb on such a surface, which largely parallels $50 \%$ inhibition; and $(b)$ the degree of saturation of the surface with increasing inhibition, which is small for the phenols, large for the benzoic and the two dihydroxybenzoic acids, and intermediate for the monohydroxybenzoic acids.

Methods in use for the study of bacteriostatic action have been discussed in a recent communication from this laboratory (Murrell \& Vincent, 1949), which also describes experience with full growth-curve methods, based substantially on those used by Hinshelwood and co-workers (Hinshelwood, 1944). Although the lengthening of the lag phase that can be demonstrated by these methods has its particular interest, inhibition during the logarithmic growth phase probably constitutes the simplest and most direct approach to the relationship between inhibitor and organism. If the full growth curve is used, the organisms must pass through a lag before reaching the logarithmic phase, so that they are in contact with the inhibitor for periods that vary with its concentration. A method has therefore been developed which exposes a large number of cells to different concentrations of the inhibitor without interruption of an established logarithmic growth phase. We record results obtained by this method with a series of simple aromatic compounds, together with data obtained by one of us (J. M. V.) for Aspergillus niger by the method already described (Vincent, 1947).

\section{EXPERIMENTAL}

Inhibitors. These comprised phenol, catechol, resorcinol, benzoic acid, o-, $m$ - and $p$-hydroxybenzoic acids, methyl $p$-hydroxybenzoate, resorcylic (2,4dihydroxybenzoic) acid and protocatechuic acid. All compounds were as used in an earlier investigation (Cavill, Phillips \& Vincent, 1949) or were obtained from commercial sources and purified. Benzoic and the monohydroxybenzoic acids were used as sodium salts; the dihydroxybenzoic acids were neutralized with the calculated volume of $\mathrm{NaOH}$ immediately before use to avoid excessive colour development. 
Organism. Bacterium aerogenes Type I, strain 32 (Murrell \& Vincent, 1949) was used throughout.

Medium. Buffered glucose peptone solution of the following composition was used: Witte peptone (0.5 \%, w/v), glucose (1 \%), $\mathrm{NaCl}(0.5 \%), \mathrm{K}_{2} \mathrm{HPO}_{4} / \mathrm{KH}_{2} \mathrm{PO}_{4}$ buffer $(0 \cdot 2 \mathrm{M})$, ascorbic acid $(0 \cdot 1 \%)$.

The initially clear medium essential for use in a photometer was obtained as follows :

(1) Peptone water. Witte's peptone (0.59 g.) and $\mathrm{NaCl}(0.59 \mathrm{~g}$.) were dissolved with heating in $100 \mathrm{ml}$. water, filtered twice under pressure through cotton wool and highgrade filter paper, autoclaved and stored in screw-capped bottles.

(2) Phosphate buffer. $2 \mathrm{M}-\mathrm{K}_{2} \mathrm{HPO}_{4}$ and $\mathrm{KH}_{2} \mathrm{PO}_{4}$ were mixed in suitable proportions to give a $\mathrm{pH}$ of $7 \cdot 0$ and autoclaved.

(8) Glucose solution $(20 \%$, w/v) was sterilized by Seitz filtration.

(4) Ascorbic acid (0.1 g.) was sterilized by exposure to $70 \%$ ethanol which was subsequently removed by evaporation.

The components were mixed aseptically in the following proportions: peptone water, $85 \mathrm{ml}$; ; phosphate buffer, $10 \mathrm{ml}$; glucose solution, $5 \mathrm{ml}$; ascorbic acid, $0 \cdot 1 \mathrm{~g}$. The mixture was stored in a cool room overnight and Seitz filtered immediately before use. All water used in the preparation of media, inhibitor dilutions and final rinsing of equipment was glass-distilled.

Inhibitor dilutions. In general, stock solutions were prepared by dissolving a known weight of inhibitor, sterilized by previous exposure to $70 \%$ ethanol (except resorcylic acid which thus became very coloured), in a calculated volume of $0 \cdot 2 \mathrm{M}$-phosphate $(\mathrm{pH} 7 \cdot 0)$ to give a concentration ten times greater than the highest required in contact with the organisms. The range of concentrations was then provided for by adding to each of a series of aluminiumcapped and optically matched tubes the requisite proportions of stock inhibitor solution and plain buffer, in each case to a total volume of $1 \mathrm{ml}$.; control tubes contained $1 \mathrm{ml}$. plain buffer. The subsequent addition of $9 \mathrm{ml}$. suspension of organisms provided the final concentrations stated in recording the results.

The low water solubility of methyl $p$-hydroxybenzoate made it necessary to dissolve this compound in $95 \%$ ethanol. Measured samples of this solution were added to the tubes to give a range of concentrations, the ethanol was evaporated under reduced pressure and, to facilitate final solution, $0 \cdot 1 \mathrm{ml}$. ethanol was added to each tube before the addition of $10 \mathrm{ml}$. bacterial suspension. Ethanol was, in these cases, added to the control tubes; in no case did it affect the organism's growth.

Inoculation, determination of growth rate and inhibition. The method of inoculation is designed to ensure that, at the time the bacterial suspension comes into contact with the inhibitor, the organisms are in, and remain in, the logarithmic phase. The method is exemplified as follows:

A series of subcultures comprises: loopful from slope to $10 \mathrm{ml}$. broth (at 5 p.m.), 1-10 ml. broth (9 a.m.), 1-10 ml. broth (11 a.m.), 10-140 ml. broth (12.30 p.m.). A sample of the last culture is withdrawn at a suitable time, the density measured photometrically and the additional time required to reach $85 \times 10^{6} \mathrm{cells} / \mathrm{ml}$. estimated. At the calculated time, $9 \mathrm{ml}$. (or $10 \mathrm{ml}$. in the case of methyl $p$-hydroxybenzoate) of this suspension are added to each of the tubes. Throughout the procedure care is taken to ensure that the organisms are not exposed to any marked change in temperature; all media and glassware are warmed to $37^{\circ}$. 
Growth can now be followed photometrically at $550 \mathrm{~m} \mu$., with the water bath $\left(37 \cdot 5^{\circ} \pm 0 \cdot 5\right)$ set alongside the instrument, taking readings of each tube in turn. The tube to follow that being read is shaken to ensure even distribution, and in time to allow bubbles to disperse from the liquid. Units of cell mass are determined from optical density by means of a standard curve for the organism.

Where a linear logarithmic increase with time is obtained, the growth rate can be calculated in the usual way and inhibition expressed as percentage inhibition $=\frac{k_{c}-k_{i}}{k_{c}} \times 100$, where $k_{c}=$ control growth rate and $k_{i}=$ growth rate in presence of inhibitor.

Inhibitors that colour the medium can, within reason, be studied by this method provided that the colour correction is not affected by the organism's growth. The addition of ascorbic acid prevented progressive colour development which would otherwise occur in the cases of catechol and protocatechuic acid due to quinone formation at $\mathrm{pH} 7$. Ascorbic acid was added in all tests in the interests of uniformity of the medium.

At the time of adding the bacterial suspension to the inhibitors, a tube of the suspension was set aside in the cool room and its $\mathrm{pH}$ measured the following morning. In all cases the value was $\mathrm{pH} 6.9$ and, since the medium was strongly buffered and there were no trends in growth rates for acid inhibitors (as would be expected for appreciable change in $\mathrm{pH}$ ), this value has been taken as representative of the medium throughout the experiments.

Statement of results. Besides comparing substances in terms of the reciprocal of the millimolar concentration giving $50 \%$ inhibition of growth rate $\left(I_{50}\right)$, dosage-response data are interpreted in terms of a hypothetical adsorption relationship between organism and inhibitor (Phillips \& Vincent, 1948).

\section{RESULTS}

Nature of growth curves. Representative curves with and without inhibitor are shown in Fig. 1. These are typical of those found throughout the present work; there is no sign of any lag or departure from linearity within the 1-2 hr. used for the establishment of the curves.

Dosage-response curves. The curves obtained by plotting inhibition directly against concentration can be interpreted for most of the inhibitors as passing through the origin (curves $\boldsymbol{A}$ and $\boldsymbol{C}$, Fig. 2, being typical). However, resorcinol (curve $B$ ) and methyl $p$-hydroxybenzoate (curve $D$ ) seem to cut the abscissa at the right of the origin, indicating either that the organism can neutralize the action of a small amount of the inhibitor or that a threshold concentration must be reached before antibacterial action occurs (cf. Hinshelwood, 1946, fig. 25; and Vincent's (1947) experience with Penicillium roqueforti and Byssochlamys fulva).

Dosage-response data for the substances not included in Fig. 2 are given in Table 1. Each inhibition value represents the result in a single tube, all concentrations of an inhibitor being tested at the one time. Experience in an exploratory series of tests generally agreed with the later, more accurate, findings. 


\section{Comparison of inhibiting potency}

The series of compounds tested in the present work, and against Aspergillus niger, are compared in cols. 1 and 2 of Table 2 on the basis of $I_{50}$ expressed more conveniently in its logarithmic form. The values for $A$. niger differ in some detail

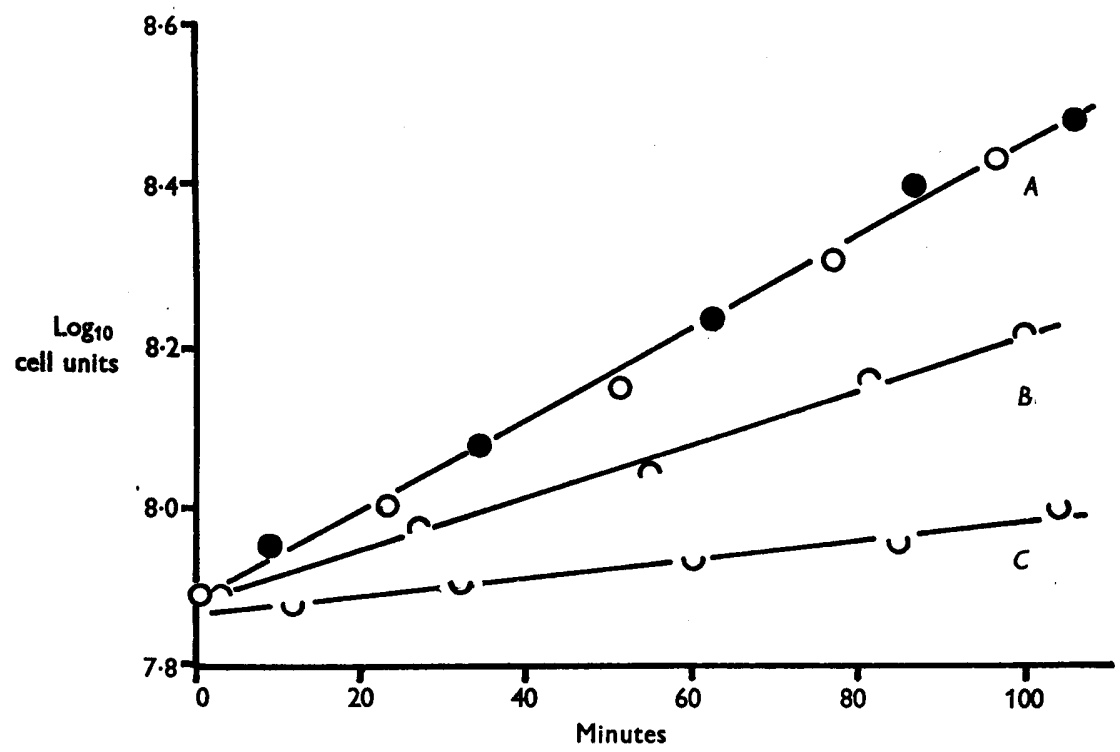

Fig. 1. Representative growth curves. $A$, control, two experiments; $B$, phenol, 6 mм.; $C$, phenol, 12 mM.

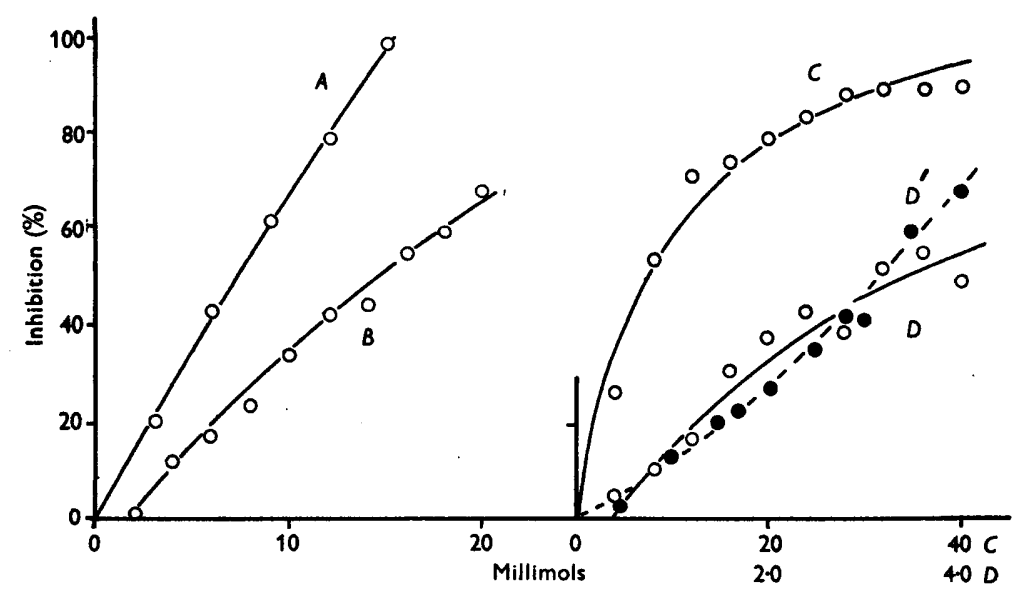

Fig. 2. Dosage-response curves. $A$, phenol; $B$, resorcinol; $C$, benzoic acid; $D$, methyl $p$-hydroxybenzoate; $D^{\prime}$, methyl $p$-hydroxybenzoate by full growth method (Murrell \& Vincent, 1949).

from those quoted by Cavill et al. (1949) and represent more exact values. They are, however, of the same order, and the earlier conclusions are substantially valid. 
Before comparing substances and taking account of the effect of substitution it is necessary, particularly with Bact. aerogenes tested at $\mathrm{pH} 6 \cdot 9$, to consider the likely effect of anionic dissociation, which is generally found to lessen inhibiting potency. At pH 6.9 the carboxylic acids will be almost entirely dissociated, whereas in tests against Aspergillus niger at $\mathrm{pH} 3.5$ practically all

Table 1. Dosage-response data for resorcinol, catechol, monohydroxybenzoic acids and resorcylic acid against Bacterium aerogenes

$y=$ percentage inhibition observed: $Y=$ percentage inhibition predicted from the adsorption relationship of equation (3).

\begin{tabular}{|c|c|c|c|c|c|c|}
\hline \multirow{3}{*}{$\begin{array}{c}\text { Concentra- } \\
\text { tion } \\
\text { (mM.) }\end{array}$} & \multicolumn{6}{|c|}{ innibition (\%) } \\
\hline & \multicolumn{2}{|c|}{ Resorcinol } & \multicolumn{2}{|c|}{ Catechol } & \multicolumn{2}{|c|}{ Salicylic acid } \\
\hline & y & $\vec{Y}$ & $y$ & $\vec{Y}$ & $y$ & $\vec{Y}$ \\
\hline 2 & - & 一 & - & - & $32 \cdot 8$ & $32 \cdot 8$ \\
\hline 4 & $11 \cdot 6$ & $10 \cdot 4$ & $18 \cdot 3$ & $18 \cdot 4$ & $56 \cdot 7$ & $\mathbf{5 3 \cdot 3}$ \\
\hline 6 & $17 \cdot 4$ & $18 \cdot 3$ & $26 \cdot 0$ & $\mathbf{2 6 \cdot 3}$ & $63 \cdot 9$ & $67 \cdot 4$ \\
\hline 8 & $23 \cdot 8$ & $25 \cdot 9$ & $34 \cdot 0$ & $\mathbf{3 3 \cdot 6}$ & $76 \cdot 0$ & $77 \cdot 5$ \\
\hline 10 & $\mathbf{3 3 \cdot 8}$ & $\mathbf{3 3} \cdot \mathbf{2}$ & $41 \cdot 1$ & $40 \cdot 4$ & $\mathbf{8 6 \cdot 0}$ & $85 \cdot 3$ \\
\hline 12 & $41 \cdot 5$ & $40 \cdot 1$ & $51 \cdot 1$ & $46 \cdot 6$ & $92 \cdot 5$ & $91 \cdot 4$ \\
\hline 14 & $43 \cdot 9$ & $46 \cdot 9$ & $47 \cdot 8$ & $\mathbf{5 2} \cdot \mathbf{3}$ & - & 一 \\
\hline 16 & $54 \cdot 1$ & $\mathbf{5 3 \cdot 3}$ & $54 \cdot 0$ & $57 \cdot 7$ & - & 一 \\
\hline 18 & $59 \cdot 2$ & $59 \cdot 5$ & $65 \cdot 5$ & $62 \cdot 6$ & - & - \\
\hline \multirow[t]{3}{*}{20} & $67 \cdot 9$ & $65 \cdot 5$ & $68 \cdot 5$ & $67 \cdot 3$ & - & 一 \\
\hline & \multicolumn{2}{|c|}{$\begin{array}{c}m \text {-Hydroxybenzoic } \\
\text { acid }\end{array}$} & \multicolumn{2}{|c|}{$\begin{array}{c}p \text {-Hydroxybenzoic } \\
\text { acid }\end{array}$} & \multicolumn{2}{|c|}{ Resorcylic acid } \\
\hline & $\boldsymbol{y}$ & $\boldsymbol{Y}$ & $y$ & $\boldsymbol{Y}$ & $y$ & $\mathbf{Y}$ \\
\hline 10 & $\mathbf{1 7 \cdot 3}$ & $15 \cdot 2$ & $21 \cdot 3$ & $20 \cdot 9$ & $39 \cdot 1$ & $39 \cdot 5$ \\
\hline 20 & $21 \cdot 9$ & $\mathbf{2 8} \cdot \mathbf{4}$ & $35 \cdot 9$ & $38 \cdot 5$ & $50 \cdot 0$ & $53 \cdot 7$ \\
\hline 30 & $42 \cdot 2$ & 39.9 & $\mathbf{5 3 . 9}$ & $53 \cdot 7$ & $69 \cdot 8$ & $61 \cdot 1$ \\
\hline 40 & 48.9 & $50 \cdot 1$ & $68 \cdot 2$ & $66 \cdot 9$ & $70 \cdot 8$ & 65.6 \\
\hline 50 & $61 \cdot 4$ & $59 \cdot 2$ & $86 \cdot 0$ & $78 \cdot 3$ & $59 \cdot 7$ & $68 \cdot 6$ \\
\hline 60 & $78 \cdot 0$ & $67 \cdot 3$ & $85 \cdot 0$ & $88 \cdot 5$ & $70 \cdot 1$ & $70 \cdot 8$ \\
\hline 70 & $79 \cdot 7$ & $74 \cdot 6$ & $95 \cdot 4$ & $97 \cdot 5$ & $75 \cdot 7$ & 72.5 \\
\hline 80 & $81 \cdot 5$ & $81 \cdot 3$ & - & - & 一 & 一 \\
\hline 90 & $85 \cdot 7$ & $87 \cdot 3$ & - & - & - & - \\
\hline 100 & 86.0 & $92 \cdot 8$ & - & - & - & - \\
\hline
\end{tabular}

the inhibitor will be in the non-ionized state. It is perhaps surprising, therefore, that the difference in $\log I_{50}$ between the two sets of experiments is so slight. It certainly appears unjustifiable to apply a correction based on the assumption that all activity resides in non-ionized molecules of the bulk phase. The extent of such corrections is shown in Table 2 (cols. 7 and 8), and if applied in the case of Bact. aerogenes to $p$-hydroxybenzoic acid would give $\log I_{50}$ of $1 \cdot 0$ compared with 0.2 for the methyl ester. This would quite reverse our experience with Aspergillus niger and general knowledge of the effect of esterification. By the same correction $\log I_{50}$ for salicylic acid would attain the unlikely value of $\mathbf{3 \cdot 4}$. To avoid such ridiculous estimates it would be necessary to regard the ionized form at least a third to a half as active as the non-ionized or to picture the inhibitor acting at a biological surface for which the $\mathrm{pH}$ is much lower than that of the bulk phase. Comparisons are made, therefore, without adjustment. 
$\log I_{50}$ data are related to water solubility (expressed as $-\log S_{w}$, where $S_{w}$ is molar water solubility) in Fig. 3. It will be seen that among the phenols and acids separately (treating the hydroxyacids as substituted acids rather than substituted phenols; cf. Cavill et al. (1949)) there is a fair inverse agreement between water solubility and inhibitory effect. As between phenols and acids, the agreement breaks down.

Table 2. Inhibition data for Bacterium aerogenes and Aspergillus niger

$B A=$ Bact. aerogenes; $A N=A$. niger.

$\log I_{50}=-\log$ millimolar concentration for $50 \%$ inhibition.

$A / K=$ ratio of effective area $(A)$ and relative inhibition $(K)$ per molcule adsorbed. $\log B=\log$ of 'biological adsorbability' of the inhibitor.

$\log S_{w}=\log$ water solubility (Cavill et al. 1949).

\begin{tabular}{|c|c|c|c|c|c|c|c|c|c|}
\hline \multirow[b]{2}{*}{ Inhibitor } & \multicolumn{2}{|c|}{$\log I_{50}$} & \multicolumn{2}{|c|}{$\boldsymbol{A} / \boldsymbol{K}$} & \multicolumn{2}{|c|}{$\log B$} & \multicolumn{2}{|c|}{ ionized } & \multirow{2}{*}{$\frac{-\log }{S_{w}}$} \\
\hline & $\begin{array}{l}B A \\
6 \cdot 9\end{array}$ & $\begin{array}{l}A N \\
\mathbf{3} \cdot 5\end{array}$ & $\begin{array}{l}B A \\
6 \cdot 9\end{array}$ & $\begin{array}{l}A N \\
\mathbf{3} \cdot 5\end{array}$ & $\begin{array}{l}B A \\
6 \cdot 9\end{array}$ & $\begin{array}{l}A N \\
3 \cdot 5\end{array}$ & $\begin{array}{r}B A \\
6.9\end{array}$ & $\begin{array}{l}A N \\
\mathbf{3} \cdot 5\end{array}$ & \\
\hline Phenol & -0.87 & -0.52 & $0 \cdot 0005$ & 0.0051 & $-2 \cdot 47$ & -0.89 & - & - & 0.2 \\
\hline Resorcinol & $-1 \cdot 18$ & -1.75 & 0.0026 & 0.0054 & $-1 \cdot 96$ & $-2 \cdot 18$ & - & - & -0.8 \\
\hline Catechol & $-1 \cdot 11$ & $-1 \cdot 17$ & 0.0050 & 0.0111 & $-1 \cdot 60$ & $-1 \cdot 08$ & - & 一 & $-0 \cdot 6$ \\
\hline Salicylic acid & -0.56 & -0.39 & 0.0070 & $0 \cdot 0109$ & -0.82 & $-0 \cdot 32$ & $4 \cdot 0$ & $0 \cdot 6$ & 1.8 \\
\hline $\begin{array}{l}m \text {-Hydroxybenzoic } \\
\text { acid }\end{array}$ & $-1 \cdot 60$ & -1.41 & $0 \cdot 0047$ & 0.0109 & $-2 \cdot 10$ & $-1 \cdot 33$ & $\mathbf{2 \cdot 8}$ & 0.2 & $1 \cdot 2$ \\
\hline $\begin{array}{l}p \text {-Hydroxybenzoic } \\
\text { acid }\end{array}$ & $-1 \cdot 44$ & $-1 \cdot 65$ & $0 \cdot 0040$ & $0 \cdot 0120$ & $-2 \cdot 05$ & $-1 \cdot 48$ & $2 \cdot 4$ & $0 \cdot 1$ & $1 \cdot 4$ \\
\hline $\begin{array}{l}\text { Methyl } p \text {-hydroxy- } \\
\text { benzoate }\end{array}$ & -0.53 & -0.18 & $0 \cdot 0090$ & - & -0.57 & - & $0 \cdot 7$ & - & - \\
\hline Benzoic acid & -0.88 & -0.30 & $0 \cdot 0086$ & 0.0138 & $-1 \cdot 00$ & $0 \cdot 04$ & $\mathbf{2 \cdot 7}$ & $\mathbf{0} \cdot \mathbf{1}$ & $\mathbf{1 \cdot 6}$ \\
\hline Resorcylic acid & $-1 \cdot 22$ & $-1 \cdot 10$ & 0.0110 & $0 \cdot 0150$ & $-1 \cdot 02$ & $-0 \cdot 63$ & $3 \cdot 7$ & $0 \cdot 4$ & $1 \cdot 8$ \\
\hline Protocatechuic acid & * & $-\mathbf{2 \cdot 0}$ & - & 0.0146 & 一 & -1.58 & - & - & $\mathbf{0 . 9}$ \\
\hline
\end{tabular}

* Preliminary tests for protocatechuic acid showed that against Bact. aerogenes this acid exhibited a very low order of activity. Shortage of material prevented further testing.

For comparative purposes it is convenient to introduce the value (Table 3)

$\Delta \log I_{50}=\log I_{50}$ of derived substance $-\log I_{50}$ of parent substance.

When this is done it is found that hydroxyl and carboxyl substitutions, other than those providing an ortho-relationship between hydroxyl and carboxyl, lead to a consistent loss of inhibitory effectiveness (groups $b$ to $d$ ). The ortho-relationship results most commonly in a gain of activity or in little loss (group $a$ ).

\section{Further interpretation of dosage-response relationships}

In an earlier paper (Phillips \& Vincent, 1948) fungistatic inhibition was interpreted as being related to adsorption expressed as the Langmuir isotherm in which

$$
A \theta=\frac{B x}{1+B x},
$$


where $\theta=$ number of molecules adsorbed/unit area, $A$ is the effective area occupied at the biological surface by each molecule adsorbed, $x$ is the millimolar concentration of substance being adsorbed, and $B$ is the ratio of constants of adsorption and desorption.

If inhibition $(y)$ is regarded as proportional to the number of molecules adsorbed,

$$
\boldsymbol{y}=\boldsymbol{K} \boldsymbol{\theta}
$$

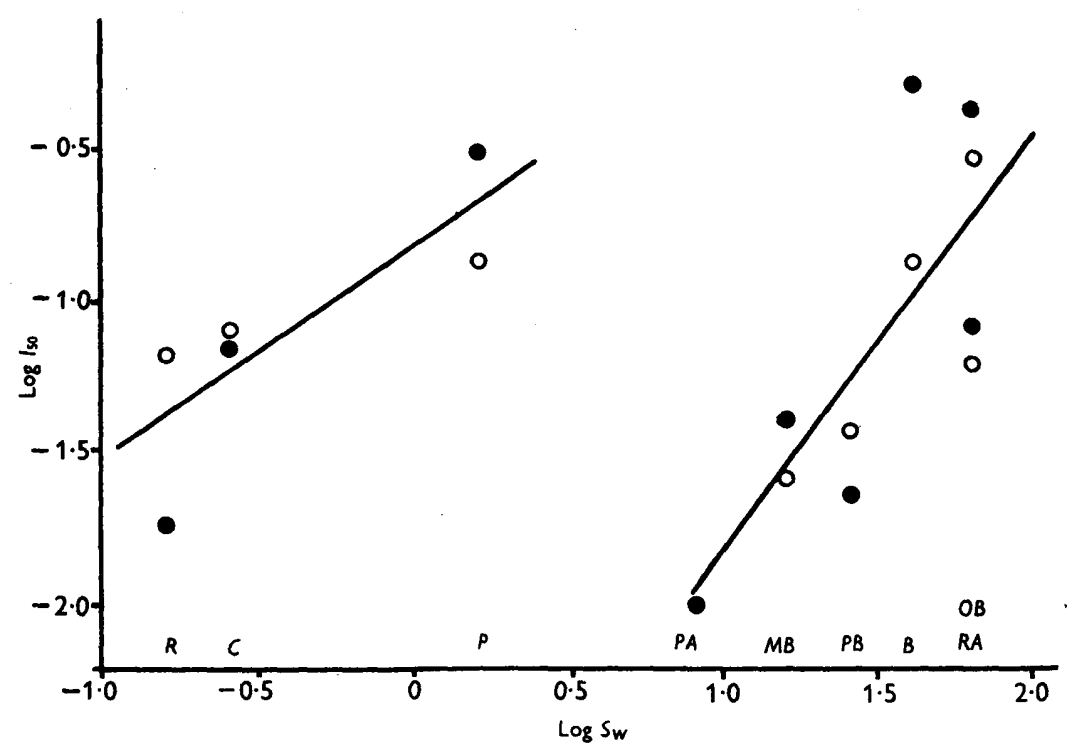

Fig. 3. Relationship between inhibitory action $\left(\log I_{50}\right)$ and water solubility $\left(-\log S_{w}\right)$. $P$, phenol; $R$, resorcinol; $C$, catechol; $B$, benzoic acid; $P B, M B$ and $O B, p-m$ - and o-hydroxybenzoic acids; $R A$, resorcylic acid; $P A$, protocatechuic acid. Open circle, Bact, aerogenes; filled circle, Aspergillus niger.

where $\boldsymbol{K}$ expresses the relative inhibitory effectiveness per molecule adsorbed. From (1) and (2),

$$
y=\frac{K}{A} \frac{B x}{1+B x} .
$$

The validity of the assumption is supported by the agreement between experimental points and the values predicted on the basis of this equation (curves $A$ and $C$, Fig. 2 and Table 1). The remaining two inhibitors can also be interpreted in terms of the same relationship if, as already noted, a reasonable adjustment is made for 'tolerance'. Apart from the general agreement between the inhibition-concentration curve and the form of the adsorption isotherm, it is possible by the use of the present bulk inoculum technique to see that a steady state condition is quickly established between organism and inhibitor (indicated by the linear curves in Fig. 1) which is in accordance with the postulate that growth-rate inhibition is being controlled by an adsorption step likely to reach a fairly rapid equilibrium. 
A linear form of equation (3) expressed as

$$
\frac{\boldsymbol{x}}{\boldsymbol{y}}=\frac{\boldsymbol{A}}{\boldsymbol{K} \boldsymbol{B}}+\frac{\boldsymbol{A}}{\boldsymbol{K}} \boldsymbol{x}
$$

has certain practical and theoretical advantages in the statistical fitting of experimental data and the evaluation of constants. In testing this linear form,

Table 3. Influence of substitutions of hydroxyl and carboxyl groups on criteria of inhibition. Comparison of parent and derived compounds

(a)

$$
\begin{aligned}
& \text { Ortho- } \\
& -\mathrm{COOH} \text { and } \\
& -\mathrm{OH}
\end{aligned}
$$

(b) Ortho$-\mathrm{OH}$ and
$-\mathrm{OH}$

(c) Meta$-\mathrm{COOH}$ and

$-\mathrm{OH}$

$-\mathrm{OH}$ and

$-\mathrm{OH}$

(d) Para-

Para-
$-\mathrm{OH}$

$-\mathrm{OH}$ and

$-\mathrm{OH}$

$B A=$ Bact. aerogenes; $A N=A$ spergillus niger. $\Delta=\log$ value derived $-\log$ value parent substance.

Benzoic acid Salicylic acid

Resorcinol Resorcylic acid $p$-HydroxyResorcylic acid

\section{Phenol}

$p$-Hydroxy-

m-Hydroxy-

Catechol

Protocatechuic

acid

Protocatechuic

benzoic acid

Phenol

Phenol

Benzoic acid

Resorcinol

m-Hydroxy:

benzoic acid

Catechol

benzoic acid

Protocatechuic

Phenol

Benzoic acid

$p$-Hydroxy-

$p$-Hydroxy-

$\boldsymbol{p}$-Hydroxy-

\begin{tabular}{|c|c|c|c|c|}
\hline \multicolumn{5}{|c|}{ Log ratio } \\
\hline \multicolumn{2}{|c|}{$\begin{array}{l}\text { Inhibiting power } \\
\left(\Delta \log I_{\mathrm{s0}}\right)\end{array}$} & \multicolumn{2}{|c|}{$\begin{array}{c}\text { Biological } \\
\text { adsorbability } \\
(\Delta \log B)\end{array}$} & \multirow{2}{*}{$\begin{array}{c}\text { Water solubility } \\
\left(-\Delta \log S_{w}\right)\end{array}$} \\
\hline$B A$ & $\overrightarrow{A N}$ & $B A$ & $\overrightarrow{A N}$ & \\
\hline $\begin{array}{l}+0 \cdot 31 \\
+0 \cdot 32\end{array}$ & $\begin{array}{l}+0.13 \\
-0.09\end{array}$ & $\begin{array}{l}+1 \cdot 65 \\
+0.18\end{array}$ & $\begin{array}{l}+0 \cdot 67 \\
-0.36\end{array}$ & $\begin{array}{l}+1 \cdot 6 \\
+0.2\end{array}$ \\
\hline $\begin{array}{l}-0.04 \\
+0 \cdot 22\end{array}$ & $\begin{array}{l}+0.65 \\
+0.55\end{array}$ & $\begin{array}{l}+0.94 \\
+1.03\end{array}$ & $\begin{array}{l}+1.55 \\
+0.85\end{array}$ & $\begin{array}{l}+2 \cdot 6 \\
+0 \cdot 4\end{array}$ \\
\hline-0.24 & $\begin{array}{l}-0.65 \\
-0.35\end{array}$ & $\stackrel{+0.87}{-}$ & $\begin{array}{l}-0.09 \\
-0.10\end{array}$ & $\begin{array}{l}-0 \cdot 8 \\
-0.5\end{array}$ \\
\hline- & -0.59 & - & -0.25 & $-0 \cdot 3$ \\
\hline $\begin{array}{l}-0.31 \\
-0.73\end{array}$ & $\begin{array}{l}-1.23 \\
-0.89\end{array}$ & $\begin{array}{l}+0.51 \\
+0.37\end{array}$ & $\begin{array}{l}-1 \cdot 19 \\
-0 \cdot 34\end{array}$ & $\begin{array}{l}-1 \cdot 0 \\
+1 \cdot 0\end{array}$ \\
\hline-0.72 & $-1 \cdot 11$ & $-1 \cdot 10$ & $-1 \cdot 37$ & -0.4 \\
\hline- & -0.83 & - & -0.50 & +1.5 \\
\hline-0.57 & $-1 \cdot 13$ & +0.42 & $-0 \cdot 49$ & $+1 \cdot 2$ \\
\hline-0.56 & $-1 \cdot 35$ & -1.05 & -1.52 & -0.2 \\
\hline-0.66 & -0.71 & -0.20 & $-0 \cdot 31$ & 0 \\
\hline
\end{tabular}

benzoic acid

Salicylic acid

Resorcylic acid

$\overbrace{\begin{array}{c}\text { Parent } \\ \text { Phenol }\end{array} \text { Derived }}^{\text {Salicylic acid }}$

o value derived -log value parent substance.

substances whose curve passes through the origin in Fig. 2, give good agreement with straight lines of positive slope (curves $A$ and $C$ of Fig. 4). However, those showing tolerance, as would be expected from the nature of the equation for the linear relationship, give $x / y$ values for the lower values of $x$ that appear to be very high and may give an apparent negative slope (resorcinol, unadjusted values, Fig. 4) that has no meaning in terms of an adsorption isotherm. When a tolerance value (estimated from a freehand drawing of the arithmetic curve) is deducted from $x$ to give a series of $x^{\prime}$ values, $x^{\prime} / y$ gives a reasonably linear relationship with positive slope (curves $B$ and $D$, Fig. 4). In these two cases adjusted values have been used for the calculation of adsorption constants.

$\boldsymbol{A} / \boldsymbol{K}$, expressing the relationship between the area occupied and percentage inhibition/molecule adsorbed, is calculated as the slope of the line of best fit in equation (4). Data for Bact. aerogenes and Aspergillus niger are given in cols. 3 and 4 of Table 2. Any ionization correction, in so far as it changes the numerical value of $x$ on both sides of equation (4), will be without effect on the calculation 
of $A / K$. Although the values for $A$. niger appear generally higher than for $B$ act. aerogenes they agree in showing certain trends related to chemical structure. Using the two organisms together as a basis for the testing of such trends, it is possible to show that phenol and resorcinol have low values that contrast with benzoic acid and the dihydroxybenzoic acids at the other end of the scale. Catechol and the monohydroxybenzoic acids occupy intermediate positions.

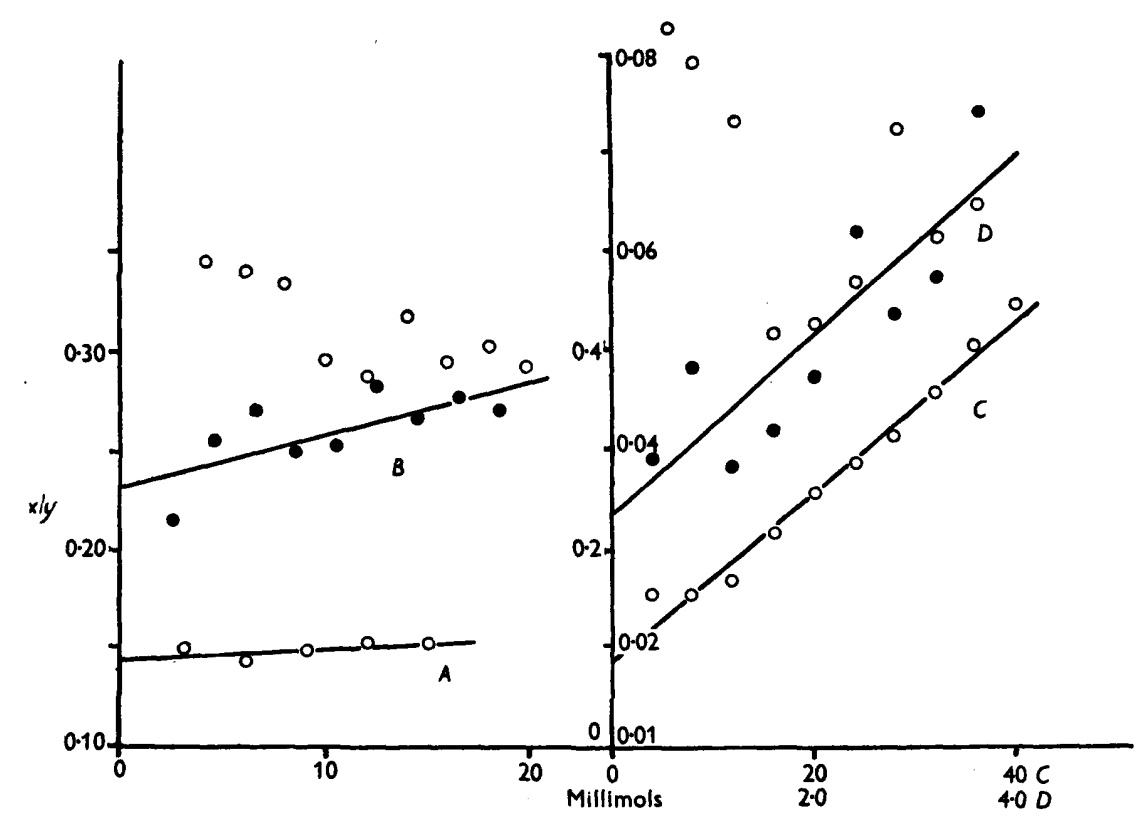

Fig. 4. Dosage-response curves-linear form. $A$, phenol; $B$, resorcinol; $C$, benzoic acid; $D$, methyl $p$-hydroxybenzoate. Ordinate: concentration $(x) /$ inhibition $(y)$. Lines $B$ and $D$ fitted to adjusted values (full circles).

The reciprocal of $\boldsymbol{A} / \boldsymbol{K}$ gives a direct measure of the relative effectiveness per molecule adsorbed on the basis of the space it occupies. Its influence is seen in Fig. 5 in which the effect of the biological adsorbability constant $(B)$ has been removed from the collection of curves by plotting $X$ in place of $x$ so that for each substance, $X=B x$. The low $A / K$ value for phenol results in a practically straight line within the range of observable inhibition, so that attainment of a high degree of inhibition occurs with very little occupation of the surface. The other parent substance (benzoic acid) has a high value for $A / K$ so that the curve flattens over at about $50 \%$ inhibition, and very much higher concentrations are required to provide $100 \%$ inhibition. From equation (3), since $\frac{B x}{1+B x} \rightarrow 1$ as the surface approaches saturation, $K / A$ sets the upper limit of $y$, so that $A / K$ must $\leqq 0.01$, if $100 \%$ inhibition be theoretically attainable. From the present data it will be seen that resorcylic acid cannot be expected to provide $100 \%$ inhibition of Bact. aerogenes, $84 \%$ being the theoretical 
upper limit. The intermediate behaviour of the remaining substances is also well shown in Fig. 5.

Solution of $\boldsymbol{A} / \boldsymbol{K}$ permits determination of $\boldsymbol{B}$ from equation (4) and data for this criterion, expressed as $\log B$, are included in Table 2. For reasons similar to those discussed in connexion with the $I_{50}$ criterion, no correction has been

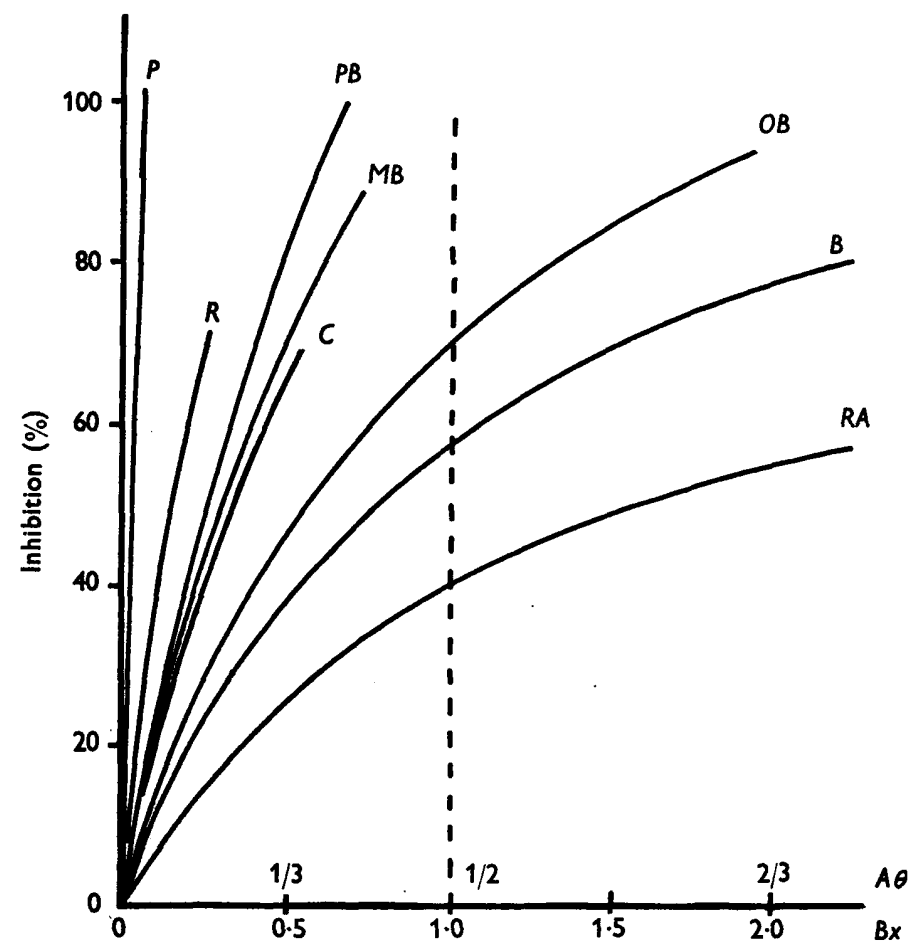

Fig. 5. Influence of $A / K$ on inhibition relative to space occupied. $P$, phenol; $R$, resorcinol; $C$, catechol; $B$, benzoic acid; $P B, M B$ and $O B, p$-, $m$ - and $o$-hydroxybenzoic acids; $\boldsymbol{R A}$, resorcylic acid; $\boldsymbol{A} \theta=$ proportion of 'biological space' occupied; $B x=$ 'biological adsorbability' $\times$ millimolar concentration.

applied for ionization. Amongst the phenols there is fair agreement between the two organisms except for phenol itself. In this case the value against Bact. aerogenes might be rather low, and it is a disadvantage of this constant that errors in $\boldsymbol{A} / \boldsymbol{K}$ are likely to cause errors in $\boldsymbol{A} / \boldsymbol{K} B$ that will accentuate the variability of $\log B$. This is particularly liable to happen for lower values of $A / K$. Having regard to the differences in $\mathrm{pH}$, the trends within the group of acids agree quite well. Apart from the low value for phenol against Bact. aerogenes, there is, as for $\log I_{50}$, a fair measure of agreement between $B$ and solubility figures among the phenols and acids separately, but no agreement between the groups.

$\Delta \log B$ can now be used as for $\Delta \log I$, the results being tabulated in Table 3. Rather more consideration is required than for $\Delta \log I$ particularly in that comparisons with phenol are likely to be discrepant between the two 
organisms because of the very low value for phenol against Bact. aerogenes. In group (a) leading to ortho-hydroxyl and carboxyl, the relationship between the two criteria is quite close for benzoic acid $\rightarrow$ salicylic acid but the other three cases involve a proportionately greater increase in biological adsorbability than in the $\log I_{50}$ criterion. The difference has its explanation in the increased $A / K$ characteristic of the monohydroxybenzoic acids compared with phenol, and resorcylic acid compared with $p$-hydroxybenzoic acid and resorcinol. In the remaining groups there is, excluding comparisons involving phenol with Bact. aerogenes, fair agreement between the trends of $\log B$ and $\log I$.

\section{DISCUSSION}

Although the mass inoculum technique developed in the present work is rather exacting, has the disadvantage of limiting the number of tubes that can be handled at one time and, like any spectrophotometric method, is affected by colour in the inhibitor, nevertheless it seems well suited for the observation of bacteriostasis within a very short time of initial exposure and without interruption of the logarithmic growth. It is likely to be subject to a minimum of uncontrolled side effects as is indicated by the comparison in Fig. 2 of data for methyl $p$-hydroxybenzoate obtained by the small inoculum, full growth-curve method (Murrell \& Vincent, 1949) with the curve obtained by the new method. It seems reasonable to conclude that the departure of the curve based on the earlier method from the typical adsorption form reflects the more complex nature of the relationship being studied, including some loss of viability at higher concentrations and an appearance of enhanced bacteriostasis.

The present paper also illustrates two approaches to the use of dosageresponse data. In the first instance we have compared substances at a convenient inhibitory level and further we have interpreted the results on the basis of an adsorption relationship. The second approach permits an analysis of the biological effect in terms of biological adsorbability, and the effectiveness relative to the area occupied by each molecule adsorbed $(A / K)$. Generally there is fair agreement between the inhibitory index $\left(I_{50}\right)$ and biological adsorbability $(B)$; but the former can be regarded as a resultant of $A / K$ operating on $B$ and some disagreement is to be expected. The phenols are characterized by a smaller $A / K$ than benzoic acid, the monohydroxybenzoic acids are intermediate, but the dihydroxybenzoic acids have an $A / K$ as great as the parent acid. Such differences in $A / K$ might be due to intrinsic differences in the effectiveness per molecule adsorbed $(K)$ or to a change in the effective area of the biological surface occupied by the molecule $(A)$ or to changes in both factors.

The authors are indebted to $\mathrm{Mr} \mathrm{C}$. Warner for preparing some of the inhibitors and to Mr J. Phillips for critical discussion of the text. The work was assisted by a grant from the Commonwealth Research Fund. 


\section{REFERENCES}

Caviul, G. W. K., Phim.ips, J. N. \& Vincent, J. M. (1949). Relationship between fungistatic activity and structure in a series of simple aromatic compounds. J. Soc. chem. Ind., Lond., 68, 12.

Hinshelwood, C. N. (1944). Bacterial growth. Biol. Rev. 19, 150.

Hrnshelwood, C. N. (1946). The Chemical Kinetics of the Bacterial Cell. Oxford: Clarendon Press.

MURREIL, W. G. \& Vincent, J. M. (1949). The esters of 4-hydroxybenzoic acid and related compounds. IV. The bacteriostatic action of $n$-alkyl-4-hydroxybenzoates. J. Soc. chem. Ind., Lond. (Accepted for publication.)

Phinirips, J. N. \& Vincent, J. M. (1948). Dosage/response relationships in mould inhibition. Nature, Lond., 161, 210.

Vincent, J. M. (1947). The esters of 4-hydroxybenzoic acid and related compounds. I. Methods for the study of their fungistatic properties. J. Soc. chem. Ind., Lond., 66, 149.

(Received 3 May 1949) 